Relato de Experiência \title{
Controle social na saúde: discutindo os resultados de uma
pesquisa com enfermeiras
}

\author{
Health-related social control study: discussion of the findings with registered nurses \\ Control social en salud: discutiendo los resultados de una investigación con enfermeras
Cássia Irene Spinelli Arantes ${ }^{1}$, Camila Campos Mesquita $^{2}$, Maria Lúcia Teixeira Machado $^{3}$, Márcia Niituma Ogata ${ }^{4}$

\section{RESUMO}

Objetivou-se, neste trabalho, relatar a experiência de um processo de discussão dos resultados de uma pesquisa sobre controle social na atenção básica à saúde. Descreve-se o processo de planejamento, desenvolvimento e avaliação de dois encontros educativos participativos realizados com 12 enfermeiras. Apresentam-se as expectativas e a avaliação das participantes; suas reflexões sobre os resultados da pesquisa; e a re-elaboração das ações de fortalecimento do controle social na saúde. Foram apontadas novas possibilidades de atuação na área e os diferentes responsáveis pela sua execução. Foram relatadas ações de responsabilidade do profissional de enfermagem, evidenciando a existência de um papel no âmbito do controle social a ser desempenhado pelo enfermeiro na atenção básica à saúde.

Descritores: Enfermagem em saúde pública; Atenção primária à saúde; Controles formais da sociedade; Conselhos de saúde; Participação comunitária

\begin{abstract}
The objective of this study was to discuss the findings of a study on social control in primary care services with registered nurses. The planning, development, and evaluation of two educational meetings with 12 registered nurses are described. Participants' expectations, reflections, and evaluations of the findings of the study are discussed. Reinstatements of actions that might strengthen health-related social control are also discussed. New decision-making approaches and key players to implement them were recommended. In addition, there were recommendations regarding the roles of registered nurses regarding social control in primary care services.

Keywords: Public health nursing; Primary health care; Social control, formal; Health councils; Consumer participation
\end{abstract}

\section{RESUMEN}

En este estudio se tuvo como objetivo, relatar la experiencia de un proceso de discusión de los resultados de una investigación sobre control social en la atención básica de salud. Se describe el proceso de planificación, desarrollo y evaluación de dos encuentros educativos participativos realizados con 12 enfermeras. Se presentan las expectativas y la evaluación de las participantes; sus reflexiones sobre los resultados de la investigación; y la reelaboración de las acciones de fortalecimiento del control social en la salud. Fueron señaladas nuevas posibilidades de actuación en el área y los diferentes responsables por su ejecución. Así mismo se relataron acciones de responsabilidad del profesional de enfermería, evidenciando la existencia de un papel en el ámbito del control social a ser desempeñado por el enfermero en la atención básica de salud.

Descriptores: Enfermeria en salud pública; Atención primaria de salud; Controles formales de la sociedad; Consejos de salud; Participación comunitaria

\footnotetext{
${ }^{1}$ Doutora em Enfermagem, Professora da Universidade Federal de São Carlos - UFSCar - São Carlos SP), Brasil,

2 Acadêmica do Curso de Graduação em Enfermagem (2002-2005) da Universidade Federal de São Carlos - UFSCar - São Carlos (SP), Brasil.

${ }^{3}$ Doutora em Saúde Coletiva; Professora do Departamento de Enfermagem da Universidade Federal de São Carlos - UFSCar - São Carlos (SP), Brasil.

${ }^{4}$ Doutora em Enfermagem; Professora do Departamento de Enfermagem da Universidade Federal de São Carlos - UFSCar - São Carlos (SP), Brasil.
} 


\section{INTRODUÇÃO}

O controle social na saúde é um dos princípios organizativos do Sistema Único de Saúde (SUS) que garante a participação da população no processo de formulação e controle das políticas de saúde no Brasil. As formas de participação são as conferências e os conselhos de saúde que funcionam nas três esferas do governo: federal, estadual e municipal ${ }^{(1)}$. Em muitos municípios, existe uma outra opção de participação direta da sociedade no SUS que, geralmente, é denominado de conselhos gestores. Estes órgãos funcionam em hospitais e ambulatórios com a função de acompanhar o funcionamento das unidades de saúde e zelar pelo atendimento das necessidades da comunidade de sua região, além de interagir com demais estruturas sociais de sua área de atuação.

Os conselhos de saúde são espaços conflituosos e de disputa pelo poder por integrarem atores com diferentes interesses, formações e projetos. São, também, potenciais espaços de construção da cidadania, pois ao exercerem seu poder participativo, os sujeitos políticos podem influenciar positivamente na implementação do SUS no nível local(2).

Por considerar que os enfermeiros possuem condições para exercer um papel importante no fortalecimento do controle social, realizamos o estudo "A atuação da enfermeira na construção do controle social no SUS: estudo em unidades de atenção básica à saúde", publicado na forma de $\operatorname{artigo}^{(3)}$. Este trabalho evidenciou que as enfermeiras da atenção básica à saúde do município de São Carlos-SP possuem concepções sobre controle social ancoradas principalmente no exercício da participação dos usuários nos conselhos gestores das unidades de saúde. Foram destacadas dificuldades que prejudicam o funcionamento efetivo desses conselhos: a falta de preparo dos profissionais e dos usuários para atuarem e os baixos resultados alcançados pelos conselhos. A pesquisa mostrou, ainda, que a prática de enfermagem voltada ao controle social na atenção básica já é uma realidade, mas precisa ser aprofundada e ampliada.

No momento da coleta dos dados dessa pesquisa ${ }^{(3)}$, assumimos o compromisso com as enfermeiras entrevistadas de que elas teriam um retorno acerca dos resultados alcançados, o que já havíamos previsto no projeto aprovado pelo Comitê de Ética em Pesquisa em Seres Humanos da Universidade Federal de São Carlos (UFSCar). Nesse sentido, decidimos planejar, desenvolver e avaliar um processo de discussão dos resultados com os sujeitos do estudo. Partimos do pressuposto de que ao conhecer e analisar coletivamente os resultados da pesquisa, as enfermeiras que atuam na atenção básica poderiam contribuir criticamente para o aprofundamento das ações já realizadas e para a formulação de novas estratégias de atuação com vistas ao fortalecimento da participação e controle social no SUS de São Carlos. É essa experiência que passamos a descrever e analisar a seguir.

\section{ENCONTROS EDUCATIVOS: PLANEJAMENTO, IMPLEMENTAÇÃO E AVALIAÇÃO}

Definimos esta experiência como uma intervenção educativa e fomos buscar suporte teórico nos princípios pedagógicos da Educação para Autonomia de Paulo Freire $^{(4)}$ na perspectiva de que ensinar não é simplesmente a reprodução de conteúdos, mas sim a criação de possibilidades para produção ou construção próprias, por meio do diálogo e de reflexão sobre a prática.

Utilizamos, também, conceitos da Educação Permanente em Saúde, que pressupõe que os processos educativos devam buscar a introdução de espaços e temas que gerem pensamento e experimentação e que o diálogo sobre as práticas e concepções vigentes no intuito de problematizálas, possibilita a construção de novas práticas ${ }^{(5)}$.

Propusemo-nos a realizar um processo educativo participativo e emancipatório e nesse sentido, trabalhamos com atividades grupais, utilizando técnicas participativas, de forma a propiciar interação e troca de conhecimentos e experiências entre os participantes, bem como a reflexão crítica sobre os resultados da pesquisa.

O convite de participação foi realizado às enfermeiras da atenção básica do município. Obtivemos o comparecimento à atividade proposta de 12 enfermeiras, das quais nem todas haviam participado como sujeito de nosso estudo.

Previamente, foi preparado um plano de ensino, no qual descrevemos os objetivos dos encontros, as atividades que seriam executadas, a previsão do tempo a ser gasto em cada uma delas e os materiais a serem utilizados.

Foram realizados dois encontros com duas horas de duração, no mês de outubro de 2005, nas dependências do Departamento de Enfermagem da UFSCar, sob a coordenação de uma das autoras que registrou todos os aspectos significativos da experiência.

O primeiro encontro educativo iniciou-se com uma dinâmica em duplas de apresentação e identificação de expectativas (técnica do cochicho). Após esclarecimentos, todas as enfermeiras assinaram o Termo de Consentimento Livre e Esclarecido, autorizando a divulgação do conteúdo dos encontros. Partimos, então, para a apresentação dos resultados de nossa pesquisa ${ }^{(3)}$. Foi feito um intervalo, e na volta abrimos a discussão sobre o trabalho apresentado. Ficamos em círculo e cada participante realizou livremente seus comentários e questionamentos. Esta atividade gerou bastante discussão e foi finalizada pela coordenadora que, por meio dos registros, ressaltou os principais pontos discutidos. 
No segundo encontro educativo, iniciamos resgatando o que havia sido discutido no encontro anterior, e partimos para a vivência de uma dinâmica que buscou valorizar o trabalho em equipe (técnica a corrida de carros: eficiência de um trabalho em equipe). Imbuídos da perspectiva do trabalho em equipe, passamos, então, a uma atividade de re-elaboração das ações incentivo e fortalecimento do controle social na saúde, que foi realizada em grupo de três ou quatro integrantes. A partir das discussões realizadas, os grupos de enfermeiras deveriam propor e descrever ações que promovessem e fortalecessem a participação social na atenção básica à saúde. Os trabalhos foram apresentados pelos grupos, por meio de cartazes elaborados. A coordenadora realizou uma síntese da apresentação de cada grupo e finalizou o encontro.

A avaliação foi realizada de forma contínua durante as atividades, por meio de registros escritos das discussões e ao final de cada encontro, utilizamos um instrumento de avaliação que possibilitou coletar o grau de satisfação das participantes em relação às atividades desenvolvidas. A partir das reflexões realizadas pelo grupo, elaboramos algumas sínteses temáticas que refletem a essência do que foi discutido sobre os resultados da pesquisa. Também realizamos uma síntese do que foi produzido pelos grupos de participantes, no que se refere à construção de propostas para atuação no controle social na saúde.

\section{OS ENCONTROS EDUCATIVOS: EXPECTATIVAS E AVALIAÇÃO DAS PARTICIPANTES}

As enfermeiras esperavam conhecer mais sobre o tema, refletir sobre sua prática e conhecer a realidade e as concepções das colegas sobre controle social na saúde (resultados da pesquisa que havia sido realizada), reafirmando, assim, a pertinência da ação educativa que se iniciava.

$\mathrm{Na}$ avaliação das participantes, os encontros educativos corresponderam às expectativas, principalmente no que diz respeito à tomada de conhecimento dos resultados da pesquisa, pois as enfermeiras valorizaram muito a apresentação de tais resultados. O retorno do trabalho concluído para os sujeitos da pesquisa foi enaltecido como algo muito importante para o seu próprio conhecimento e para a melhoria da atuação da enfermeira na atenção básica, com vistas ao fortalecimento do controle social.

A troca de experiências e o espaço de discussão de opiniões e experiências foram apontados como muito importantes para reflexão sobre a consolidação dos conselhos gestores e busca conjunta de soluções para problemas comuns às enfermeiras de diferentes unidades básicas.

As técnicas de dinâmicas de grupo e a forma como os encontros foram desenvolvidos agradaram às participantes, pois houve uma construção coletiva, sem expô-las individualmente ou causar constrangimentos, deixando-as muito a vontade para as manifestações.
O processo de discussão e re-elaboração das ações foi muito valorizado pelas participantes, na medida em que elas tiveram a oportunidade de refletir sobre a sua atuação como enfermeira nas ações de controle social, o que poderá resultar em melhor desempenho profissional no exercício do trabalho na atenção básica à saúde.

\section{CONTROLE SOCIAL NA ATENÇÃO BÁSICA: REFLEXÕES SOBRE OS RESULTADOS DA PESQUISA}

As reflexões e troca de experiências sobre os resultados da pesquisa ${ }^{(3)}$ ficaram em torno da configuração e atuação dos conselhos gestores das unidades, evidenciando-se como o foco de preocupação das enfermeiras.

Falta resolutividade às questões levantadas nos conselhos de saúde

As participantes enfatizaram na discussão a falta de retorno do gestor municipal, às questões levantadas nos conselhos gestores locais. Para as participantes, as ações voltadas para o controle social, dependem, em grande parte, do encaminhamento que a Secretaria Municipal de Saúde dá às questões e necessidades identificadas.

Parece não haver uma definição clara dos papéis dentro dos conselhos gestores. Demonstraram não compreender, por exemplo, o papel do conselheiro representante do gestor municipal. Muitas ações parecem ser realizadas apenas para cumprir determinações burocráticas, não resultando em qualquer ação participativa efetiva, voltada para as necessidades levantadas nas reuniões. Sem a clareza dos objetivos dos conselhos e sem o conseqüente compromisso, o controle social, através dos conselhos de saúde desvia-se do interesse comum da sociedade e da cidadania, fragiliza-se e perde credibilidade $^{(6)}$.

É fundamental que se tenha o apoio e compromisso dos gestores municipais com as propostas levantadas nos conselhos locais, pois a conduta do gestor municipal é muito importante para estimular a participação cidadã e reforçar o compromisso ético com a população ${ }^{(7)}$.

\section{A atuação dos conselheiros}

As participantes demonstraram descontentamento com a participação dos conselheiros, especialmente os representantes dos usuários e dos trabalhadores da saúde. Relataram que os mesmos não são orientados quanto ao seu papel nos conselhos gestores, gerando assim malentendidos como usos do cargo de conselheiro para conseguir vantagens na unidade, como: melhor atendimento, consultas médicas mais rápidas, entre outras. Salientaram que as reivindicações dos conselheiros usuários versam, quase sempre, sobre a reivindicação de um número maior de consultas e médicos e a garantia de medicamentos, denotando que também precisam de 
orientações quanto ao modelo assistencial do SUS.

Outra conseqüência que pode estar relacionada à falta de orientação sobre o funcionamento do conselho e sobre o papel dos conselheiros, é a desistência de continuar na função de representante, havendo muita rotatividade dos conselheiros.

A discussão sobre a participação efetiva tem mostrado que os conselhos buscam se constituir em instrumentos de participação e controle social, mas em diversos aspectos, ainda são frágeis ${ }^{(8)}$. A cultura de não participação, a falta de consciência política e o medo de discriminação são fatores que contribuem para que a participação nos órgãos colegiados seja reduzida ${ }^{(9)}$. Em nossa sociedade, precisamos construir o respeito e o valor às representações coletivas, e atuar na formação de sujeitos que sejam capazes de defender os interesses sociais.

\section{A contribuição da enfermeira nos conselhos}

O processo de discussão evidenciou que as enfermeiras participantes apresentaram dificuldade em apontar como poderiam contribuir para melhorar a atuação dos conselhos gestores. A participação da enfermeira como membro do conselho gestor parece que, muitas vezes, ocorre para o cumprimento de uma determinação da Secretaria Municipal de Saúde, pois por mais que acreditem no potencial dos conselhos e vejam sua importância, sentem-se desmotivadas para participar. Novamente, atribuem tal situação à falta de apoio da gestão municipal para a resolução das necessidades levantadas pelos conselhos.

Consideraram que o papel da enfermeira está pautado na orientação de trabalhadores e usuários e na divulgação do conselho como um espaço de participação para os usuários, ressaltando a responsabilidade de representar a comunidade. Algumas participantes acreditam que seja papel também da enfermeira da atenção básica, preservar e manter funcionando os conselhos gestores, porém, precisam, ainda, aprender a atuar neste sentido. Esta realidade remete à necessidade de processos educativos permanentes que ocorram ao mesmo tempo em que se exercite a participação ${ }^{(2)}$.

\section{(RE)ELABORANDO AÇÕES DE FORTALE- CIMENTO DO CONTROLE SOCIAL NA SAÚDE}

Após tomarem conhecimento e discutirem os resultados da pesquisa, as enfermeiras passaram a reelaborar, coletivamente, as ações que visam ao fortalecimento do controle social na realidade das unidades de atenção básica à saúde.

Várias ações apresentadas individualmente pelas enfermeiras entrevistadas na pesquisa realizada apareceram novamente na produção coletiva, como:
- Divulgar para a população em geral e trabalhadores informações sobre o que é controle social e a existência dos conselhos de saúde;

- Capacitar os conselheiros (trabalhadores e usuários);

- Divulgar nos meios de comunicação e nas entidades do bairro, as reivindicações e as conquistas de cada conselho gestor;

Além disso, novas possibilidades de atuação foram elaboradas pelas participantes dos encontros, tais como:

- Trocar experiências entre as unidades onde o conselho é atuante, mantendo uma integração entre as unidades e também com a Secretaria de Saúde;

- Buscar novos conhecimentos e atualização sobre o tema;

- Envolver os demais membros da equipe de saúde e as demais secretarias, principalmente a de educação, na orientação e incentivo ao controle social;

- Garantir espaço para as reuniões dentro da unidade de saúde;

- Buscar retorno para as solicitações feitas nos conselhos gestores locais;

- Garantir que haja representantes dos bairros no conselho municipal de saúde e solicitar a sua participação nas respectivas reuniões de conselho local.

As enfermeiras avaliaram que a integração entre os conselhos gestores, as unidades de saúde e a Secretaria Municipal de Saúde são estratégias de promoção da participação social, uma vez que permitem a troca de experiências entre eles.

A visualização da necessidade de se buscar o envolvimento dos demais membros da equipe de saúde e da Secretaria de Educação, nos processos participativos e de se divulgar as reivindicações e conquistas dos conselhos gestores, nos meios de comunicação demonstrou uma compreensão de que o incentivo ao controle social vai além da atuação da enfermagem e dos muros da unidade de saúde. Contudo, as enfermeiras também se colocaram como responsáveis ou coresponsáveis na execução de várias ações.

O reconhecimento da importância da presença dos conselheiros municipais nos conselhos gestores locais e de se garantir respostas às solicitações realizadas por tais conselhos apontam para a necessidade de que haja interlocução entre os diferentes conselhos e entre estes e o gestor municipal para que se possam transformar as necessidades de saúde da população em políticas e ações.

\section{CONSIDERAÇÕES FINAIS}

A experiência de se discutir os resultados de uma pesquisa com os sujeitos que dela fizeram parte dela significou muito mais do que o retorno de dados científicos à realidade empírica ou o cumprimento de um compromisso assumido, pois propiciou momentos de interação, aprendizagem e 
construção de novos conhecimentos.

A opção de realizar encontros pedagógicos, fundamentados na Educação para Autonomia, com a utilização de técnicas participativas, obteve uma avaliação bastante positiva das participantes que se sentiram a vontade para expor sua opinião, além de proporcionar o diálogo, a problematização e a construção de novas perspectivas de atuação para o controle social na saúde.

$\mathrm{Na}$ discussão sobre os resultados da pesquisa, alguns temas foram aprofundados pelas participantes e houve a re-elaboração das ações de fortalecimento do controle social. Além de apontarem outras possibilidades de atuação, visualizaram os diferentes atores responsáveis pela

\section{REFERÊNCIAS}

1. Brasil. Lei n ${ }^{\circ} 8080$, de 19 de setembro de 1990. Dispõe sobre as condições para promoção, proteção e recuperação da saúde, a organização e o funcionamento dos serviços correspondentes e dá outras providências. Diário Oficial da União, Brasília (DF) 1990; 20 set. Seção 1: 18055-9.

2. Vanderlei MIG, Witt RR. Conselhos de saúde: espaços de participação social, constituição de sujeitos políticos e coprodução de sujeitos coletivos. Saúde Debate. 2003;27(64):131-7.

3. Arantes CIS, Mesquita CC, Machado MLT, Ogata MN. O controle social no Sistema Único de Saúde: concepções e ações de enfermeiras da atenção básica. Texto \& Contexto Enferm. 2007;16(3):470-8.

4. Freire P. Pedagogia da autonomia: saberes necessários à prática educativa. 30a. ed. São Paulo: Paz e Terra; 2004. sua execução, transcendendo os limites da enfermagem e da área da saúde. Por outro lado, atribuíram várias ações como de responsabilidade também do profissional de enfermagem, mostrando a existência de um papel no âmbito do controle social a ser desempenhado pela enfermeira da atenção básica à saúde.

Consideramos a experiência muito positiva e acreditamos que processos educativos semelhantes deveriam ocorrer de forma contínua, pois a educação para o controle social na saúde precisa estar inserida em uma política de educação permanente que vise à formação dos diferentes segmentos: usuários, trabalhadores e gestores para a participação social no SUS.

5. Ceccim RB. Educação permanente em saúde: desafio ambicioso e necessário. Interface Comun Saúde Educ. 20042005;9(16):161-77.

6. Rodrigues NS, Ferreira BMS, Cunha CAC, Reis D, Cartaxo F, Ribeiro GC, et al. A prática do controle social através dos conselhos de saúde. Divulg Saúde Debate. 2000;(22):71-89.

7. Dornelles S, Locks MT. Controle social: de quem? Para o quê? Saúde Debate. 2003;27(65):348-57.

8. Gaio TC, Faria EM. Cidadania, participação e controle social: requisitos para efetivar o SUS: reflexões. Texto \& Contexto Enferm. 2000;9(2):264-73.

9. Gonçalves ML, Almeida MCP. Construindo o controle social e a cidadania em uma experiência concreta: o Conselho Municipal de Saúde (CMS) de Ribeirão Preto (SP). Saúde Debate. 2002;26(61):161-75. 